\title{
Los gestores de la reciente gran recesión mundial
}

\author{
Pedro Quintín Quílez ${ }^{1}$ \\ Docente e investigador de la Universidad del Valle, Cali, Colombia \\ pedro.quintin@correounivalle.edu.co
}

\section{Mirowski, Philip. Nunca dejes que una crisis te gane la partida. Barcelona: Ediciones Deusto, 2014 [1 ${ }^{a}$ ed. en inglés, 2013; trad. Blanca Ribera de Madariaga]}

La carátula de la edición española del último libro de Philip Mirowski puede llevar a engaño. Sobre un fondo negro se destaca la nítida imagen -en plano medio corto- de tres hombres bien trajeados y con pinta de banqueros que miran, fija y decididamente, a los ojos del lector, retándolo; debajo, el título en grandes letras blancas: "Nunca dejes que una crisis te gane la partida". A primera vista recuerda a esos libros que llenan los estantes cada vez más largos de la sección de autoayuda y superación de nuestras librerías más populares. Sin embargo, hallado inesperadamente en la mesa de novedades de la sección dedicada a la ciencia económica, la primera impresión es de extrañeza: o bien el librero se ha equivocado de ubicación, o bien la economía ha sucumbido finalmente al sino de los tiempos y reorienta su quehacer a ofrecer, a un módico precio, alguna vía salvífica definitiva para la crisis.

El librero no se ha equivocado. Tampoco se trata de un libro de autoayuda. La carátula es una ironía premeditada. Para llegar a esa conclusión basta con sopesar las 587 páginas del libro — cantidad sin duda excesiva para un texto de autoayuda-, leer con algo más de atención el subtítulo — “¿Cómo ha conseguido el neoliberalismo, responsable de la crisis, salir indemne de la misma?"- y descubrir que los retratados no son sino los economistas Alan Greenspan (antiguo presidente de la Reserva Federal de Estados Unidos), Robert Rubin (exsecretario del Tesoro y banquero) y Larry Summers (exsecretario del Tesoro, profesor y expresidente de la Universidad de Harvard). No sabemos si la idea del diseño de la carátula procede

1 Licenciatura en Antropología Cultural. Doctor en Geografía e Historia —especialidad Antropología Social一.

cC) (i) Este trabajo está bajo la licencia Creative Commons Attribution 3.0 
de su autor o de la editorial, pero lo cierto es que llama la atención: esperemos que piquen bastantes lectores incautos tratando de encontrar la piedra filosofal para salir de alguna crisis y, sin pretenderlo, se lleven el valioso libro de un historiador y filósofo de la ciencia sobre los más recientes desatinos de los economistas y su impacto en la política económica a nivel planetario².

Pues el origen del libro, cuenta el autor, está en su sensación de estar inmerso en una de esas angustiantes pesadillas de las que no se puede despertar, en este caso no solo respecto del incierto futuro abierto por la crisis financiera del año 2008 y el hecho de que quienes han sido sus principales causantes hayan sido designados para la tarea de buscar soluciones para su superación: el pánico procede, sobre todo, de la constatación de que las herramientas intelectuales para luchar contra la crisis son las mismas que nos han llevado a ella. Tratando de encontrar una vía para salir de este mal sueño, Mirowski propone adelantar una "historia y sociología del conocimiento de la crisis". Para ello, reconstruye la forma en que durante las últimas décadas han ido confluyendo en Estados Unidos grupos de interés económico, pensadores neoliberales y economistas -que no son lo mismo ni están de acuerdo en todos los puntos- en la tarea de producir y generalizar una particular visión del mundo y erigir exitosamente una barrera protectora ante cualquier intento de impugnación de dicha visión. El resultado constituye una pormenorizada descripción de las principales estrategias puestas en juego por estos grupos (el "manual general de estrategias neoliberales"), cuyo conocimiento y crítica sería para Mirowski la única posibilidad de derrotarla o, cuanto menos, de relativizarla en procura de alguna forma alternativa de organización económica.

\section{Think tanks y la doble verdad de la economía neoliberal}

El texto se sitúa así en una línea de continuidad respecto de libros críticos de las derivas de la ciencia económica —como Zombie Economics (2010) de John Quiggin - o de documentales sobre los orígenes de la crisis financiera - como Inside Job (2010) de Charles Ferguson-. Sin embargo, más que describir el surgimiento y la evolución de la crisis, o de denunciar a sus causantes, Mirowski intenta desentrañar las principales estructuras políticas, académicas y económicas que han permitido la existencia de tales actores y han facultado su accionar. Así, por ejemplo, el segundo capítulo describe el proceso de conformación y desarrollo del grupo de pensadores organizados después de la Segunda Guerra Mundial

2 La edición original en inglés tiene otra carátula no menos llamativa: muestra la sección de rascacielos -el área financiera, donde se suelen ubicar las grandes corporaciones y bancos- de una indeterminada gran ciudad moderna al borde de un profundo y amenazador acantilado: remite a los afiches promocionales de esas películas cuyo argumento gira en torno a un inminente y catastrófico fin del mundo. Las obras de este investigador norteamericano y profesor de la Universidad de Notre Dame (Indiana) suelen llevar títulos sugestivos: por ejemplo, More Heat than Light: Economics as Social Physics (1989) acerca de las influencias mutuas entre la física y la economía, especialmente en el origen de la economía neoclásica; Machine Dreams: Economics Becomes a Cyborg Science (2002) sobre la influencia de la ciencia militar y la robótica en la teoría de juegos y la economía computacional; o Science-Mart ${ }^{T M}$ : Understanding the Era of Globalized Commercialized Science (2011) sobre la creciente comercialización de la ciencia. 
alrededor de la Sociedad Mont Pèlerin: originalmente centrada en la defensa de la democracia y los derechos humanos pero con una perspectiva política deslavazada y llena de contradicciones internas (entre liberalismo, conservadurismo, libertarismo e incluso socialismo), ha evolucionado hasta convertirse en la principal matriz think tank neoliberal con un cuerpo sólido y bastante coherente de ideas y, sobre todo, un programa político nítido. Curiosamente, la fortaleza de su ideario no reposa en su mayor capacidad para describir o siquiera para interpretar el mundo: su éxito está más bien en el tipo de organización elitista implementada para sostenerlo, en las fórmulas de selección de sus nuevos miembros (y por tanto, de exclusión de miradas disidentes) y en la densa red de vínculos estrechos - pero discretos-que mantiene con las instituciones (económicas, políticas y mediáticas) más poderosas a nivel internacional y, en especial, con la economía académica dominante que lo ha dotado de una pátina de seriedad y objetividad.

Enterado el lector de que la pertenencia a esta sociedad no se rige precisamente por el tan reclamado orden espontaneo del mercado que ellos mismos predican sino por la dedocracia, no puede sorprenderlo mucho el hecho de que se asuma descaradamente en su seno la existencia de una "doble verdad" sobre la economía: una, esotérica, para quienes forman parte del selecto grupo y otra, exotérica, destinada al resto del mundo. Esa versión pública se basa en la ignorancia y la confusión, bajo la idea de que no hace falta saber mucho acerca del mercado más que el dogma de que todo funciona mejor si se lo deja actuar por sí mismo. Por tanto, nada de intervenir... excepto cuando es necesario para permitir el óptimo funcionamiento del mercado de acuerdo al juicio de los que verdaderamente saben cómo son las cosas, es decir, de quienes tienen el conocimiento esotérico. En definitiva, no se trataría sino de la traslación al ideario del mercado capitalista de la teoría de Carl Schmitt acerca de la excepción política.

Esa ideología que no parece tener ideología ha dado lugar a una economía cotidiana que el autor desbroza rápidamente: apoyándose en la propuesta foucaultiana sobre la constitución de una subjetividad individual homogeneizada en el capitalismo (concepción empresarial de la propia personalidad, extensión del cálculo a todas las esferas de la vida, búsqueda activa de recompensas, valoración del riesgo, etc.), la lleva más allá al insistir, sin embargo, en que el mercado no es un agente que se imponga homogéneamente a todos, sino que algunos, como los miembros de ese grupo selecto, "se absuelven a sí mismos de su dominio". El mercado es resultado de interacciones y luchas sociales, pero no todos participan en ellas con las mismas bazas ${ }^{3}$. Algunos - la gente del común- juegan con una personalidad fragmentada y con graves disonancias cognitivas, con lo que dejan el camino libre a quienes son capaces de acciones coordinadas de largo aliento, de tal forma que incluso quienes se rebelan terminan por jugar a favor del mercado - como sucede con lo que él denomina "buycotting" (la

3 En este punto Mirowski ha mostrado reiteradas discrepancias con autores que se ubican en la perspectiva de la economía performativa (como Donald Mackenzie, Michel Callon o Fabian Muniesa); véase, por ejemplo, Ph. Mirowski y E. Nik-Khah, "Markets made flesh. Performativity, and a problem in science studies, augmented with considerations of the FCC auctions", en D. Mackenzie et al., Do Economists Make Markets? On the Performativity of Economics, Princeton NJ, Princeton University Press, 2007, pp. 190-224. 
pretensión de boicotear comprando) o con el "murketing" (las compras turbias orientadas desde redes sociales electrónicas supuestamente neutrales y abiertas a todos)-.

\section{Los economistas: la paradoja de una ocupación anticíclica}

Pero la detallada descripción de todo lo anterior no constituye sino la primera mitad del libro. El resto se dedica a estudiar a otro colectivo, participe principal de este proceso, que "ha salido indemne de la crisis, a pesar de que su comportamiento antes y después de la recesión fue menos que ejemplar". No se enriqueció con la crisis, pero tampoco la sufrió sino que sus miembros salieron reforzados de ella "como auténticos arsenales de sabiduría, o, al menos, profetas de la prosperidad": la profesión económica ortodoxa contemporánea o "neoclásica" (pp. 217-218). Es cierto que, para sus miembros, el tránsito por la crisis ha sido momentáneamente tormentoso: partiendo de la inicial tolerancia cero con la heterodoxia antes de la crisis, pasaron a dar muestras de confusión e ignorancia durante la etapa álgida de la crisis y luego a enzarzarse en feroces ataques entre ellos para, finalmente, "en lugar de pedir una tregua y abrir sus horizontes intelectuales para considerar una descripción alternativa en respuesta a los acontecimientos, [apresurarse] a reinstaurar el statu quo previo" con apenas un par de concesiones insignificantes (p. 219). Mirowski retoma en este punto las paradójicas palabras del economista Robert Barro: "De hecho, la crisis ha elevado claramente la demanda de servicios económicos y economistas. No hay ocupación más anticíclica que la del economista".

Mirowski ofrece en esta parte una sociología de los economistas describiendo los comportamientos profesionales y personales de algunos de los principales miembros del colectivo y poniendo especial atención a sus afiliaciones y relaciones con otros sectores, carreras académicas, declaraciones, desmemorias y giros discursivos estratégicamente elaborados; luego revisa el trasfondo de sus afirmaciones doctrinales y la panoplia de enrevesados argumentos y barreras organizativas con que protegen su peculiar perspectiva sobre el mundo.

Por ejemplo, y entre otras muchas cosas, el lector encontrará cómo las culpas de la crisis les han sido atribuidas por este colectivo a perversos comportamientos personales e idiosincráticos dentro del gremio y no a la estructura colectiva que los facilitó: un deficiente sistema de enseñanza de la economía, un tejido de redes destinadas a la cooptación profesional por parte de las altas esferas de las finanzas privadas, su vinculación creciente con las disciplinas de la gestión social y la administración dando como resultado la ocupación de los puestos políticos y técnicos decisorios - por ejemplo, en los múltiples niveles de la Reserva Federal-y el estrechamiento de lazos con los núcleos duros del pensamiento neoliberal. De todo ello resultan buenos ejemplos las figuras de Alan Greenspan (protagonista central del trio de la carátula) o Benjamin Bernake - presidente de la Reserva Federal bajo las presidencias de Bush y Obama-, tratadas en extenso en el libro y que, una vez desnudadas de sus ostentosos ropajes, pierden buena parte de su lustre y autoridad académica al ponerse en evidencia, sobre todo, su gran capacidad para medrar en los altos círculos políticos y económicos más que su habilidad como economistas. 
De forma progresiva, Mirowski desgrana con gran detalle el arsenal de mecanismos de defensa usados para proteger a la profesión y, con ella, al dogma dominante y más funcional con el neoliberalismo, gracias al papel activo del sector financiero y de las instituciones económicas nacionales e internacionales, en especial mediante la puesta en práctica de la agnotología, es decir:

\begin{abstract}
El estudio centrado en la fabricación intencional de la duda y la incertidumbre en la población en general por motivos políticos específicos [...] Una serie de técnicas y tecnologías para utilizar e influir en disciplinas académicas que existen separadamente con el fin de reforzar la impresión de una controversia inexorable, en la que las disputas reales son marginales, causando estragos en la percepción que se tiene desde fuera de la forma de las doctrinas ortodoxas, y creando un grupo paralelo de portavoces y emisarios de ideas beneficioso para los intereses financieros entre bastidores [...] Los primeros ejemplos de agnotología se centraron en casos de las ciencias naturales, más concretamente, en las controversias políticas sobre las consecuencias del cáncer por humo del tabaco, los sistemas antimisiles de la Guerra de las Galaxias, la teoría de la evolución, la eficacia de las farmacéuticas, y las causas y consecuencias del calentamiento global" (pp. 307-308).
\end{abstract}

La generalización de esta hermenéutica de la sospecha ayuda a impulsar, en este caso, la idea de que no hay mayores certezas entre los especialistas sobre las causas, consecuencias y posibles vías de salida a la crisis - como se dio a entender tras los debates alrededor del Programa de Asistencia para Activos Problemáticos [TARP] en el año 2008 o de la Comisión de Investigación de la Crisis Financiera entre el 2009 y el 2011, finamente descritos por Mirowski- y que, por lo tanto, es mejor esperar a que el asunto se resuelva por sí mismo. Es decir, esperar a que lo resuelva "el mercado". En definitiva, a la gente del común nos toca confiar en el buen hacer de los economistas que no son capaces de ponerse de acuerdo más que para recomendar más de lo mismo: entregarse al mercado. Por cierto, a esta faena - insiste - no solo han contribuido economistas claramente neoliberales y conservadores, sino también aquellos que han pretendido situarse en la otra orilla política sin abandonar los principios dominantes de la ciencia económica, como Joseph Stiglitz o Paul Krugman: "Los preceptos agnotológicos sugieren que la profesión económica ortodoxa ha sido útil para los proyectos neoliberales porque llena la esfera del discurso público relativo a la crisis con un exceso de ruido y duda" (p. 396)

Aunque en su versión castellana el libro tiene algunos problemas formales (de digitación, básicamente) y la redacción es en algunos apartes confusa, su lectura -que no siempre es fácil para un neófito en la ciencia económica— señala

4 Tampoco se libran de críticas quienes han aspirado a hallar vías alternativa al capitalismo, como el movimiento Occupy Wall Street, al ser incapaces de atender a la fuerte estructura organizativa y las redes de apoyo en diferentes esferas sociales que están detrás del neoliberalismo y su capacidad de dirección y movilización social: "Los rebeldes se manifestaron contra el poder, pero aparentemente no tenían idea alguna de cómo funcionaba el poder en realidad" (p. 434). De hecho, las protestas habrían sido cooptadas mediante las ya citadas estrategias de murketing: "Usted consigue expresarse; ellos [los capitalistas] obtienen dinero" (p. 440). 
vías fundamentales y sólidas para elaborar balances más equilibrados de la crisis, por fuera tanto de señalamientos personales como de teorías conspiratorias sin evidencia.

Ahora bien, también es cierto que, una vez leído el libro, el lector quizás sienta cierta desazón y esté tentado a pensar que más habría valido que ese libro hubiera estado en la sección de economía de la librería porque la disciplina hubiera sucumbido al sino de los tiempos: con toda probabilidad los efectos de los consejos de un sanador de almas o de un coach manager habrían sido mucho menos dolorosos y duraderos que los producidos por las acciones propiciadas por esa gran sección dominante de la ciencia económica que describe Mirowski. Porque si algo han sabido hacer bien los principales protagonistas de la historia expuesta en el libro ha sido precisamente aprovechar la crisis para lograr lo que nunca antes habían pensado posible: salir airosos y reforzados. No por casualidad las palabras originalmente pronunciadas por Winston Churchill, pero retomadas premonitoriamente por Rahm Emanuel (político demócrata, exrepresentante en la Cámara, Jefe de Gabinete en la Casa Blanca con Obama y actual alcalde de Chicago) a propósito de las posibles salidas a la crisis económica, son las que dan título al libro ("Nunca dejes que una partida te gane la partida"), que continúan así: "Y con ello quiero decir que es una oportunidad para hacer cosas que piensas que antes no podías hacer". 